\title{
SPACE SCIENCE REVIEWS
}

VOLUME 27 Nos. 3/4 NOVEMBER/DECEMBER 1980

Editorial Committee:

S. I. Akasofu,W.J. G. Beynon, C. de Jager, and S. I. Rasool

SPECIAL ISSUE

\section{STELLAR HYDRODYNAMICS}

Proceedings of the 58th Colloquium of the International

Astronomical Union held in Los Alamos, U.S.A., August 12-15, 1980

Edited by ARTHUR N. COX and DAVID S. KING

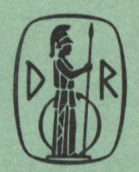




\section{SPACE SCIENCE REVIEWS}

Editorial Dr S. I. Akasofu, Geophysical Institute, University of Alaska, Fairbanks, Alaska 99701, Committee: U.S.A.

Main responsibility: Magnetosphere and Interplanetary Matter.

Prof. W. J. G. Beynon, University College of Wales, Dept. of Physics, Penglais, Aberystwyth, Cards., Wales.

Main responsibility: The Earth's Neutral Atmosphere and Ionosphere.

Prof. C. de Jager, Space Research Laboratory of the Astronomical Institute, Beneluxlaan 21, Utrecht, The Netherlands.

Main responsibility: Astronomy.

Dr S. I. Rasool, Chief Scientist, Office of Space and Terrestrial Applications, Code E-1, NASA, 600 Independence Avenue, S.W., Washington D.C. 20546, U.S.A.

Main responsibility: The Planetary System

Editorial Term ending December 1980:

Board: $\quad$ W. I. Axford, Lindau-Harz, F.R.G., C. G. Fälthammar, Stockholm, J. Geiss, Bern, R. Giacconi, Cambridge, Mass., B. Hultqvist, Kiruna, Sweden, G. Ludwig, Washington, D.C., B. M. McCormac, Palo Alto, Calif., F. B. McDonald, Greenbelt, Md., M. Nicolet, Brussels.

Term ending December 1981 :

R. L. F. Boyd, Dorking, Surrey, A. Galeev, Moscow, W. Heikkila, Dallas, Tex., H. C. v.d. Hulst, Leiden, S. L. Mandelstam, Moscow, H. S. W. Massey, London, J. Quenby, London, Z. Svestka, Utrecht, G. J. Wasserburg, Pasadena, Calif.

Term ending December 1982 .

A. G. W. Cameron, Cambridge, Mass., G. B. Field, Cambridge, Mass., S. Hayakawa, Nagoya, D. Lal, Ahmedabad, M. Ya. Marov, Moscow, F. Pacini, Firenze, S. K. Runcorn, Newcastle-upon-Tyne, V. Vasyliunas, Lindau-Harz, F.R.G., D. J. Williams, Boulder, Colo.

Term ending December 1983:

M. Calvin, Berkeley, Calif., K. D. Cole, Victoria, Australia, R. Lüst, München, A. P. Mitra, New Delhi, L. E. Peterson, La Jolla, Calif., M. A. Pomerantz, Newark, Delaware, J. G. Roederer, College, Alaska, R. Z. Sagdeev, Moscow, L. I. Sedov, Moscow.

Publication programme, 1980: 3 volumes (12 issues), monthly. Subscription price per volume: Dfl. 189,-, including postage (U.S. \$99.50). Private individuals (no institutions, laboratories, libraries, etc.) may subscribe at the reduced rate of Dfl $60,-(\$ 30.00)$. They should declare that the subscription is for their own personal use, that it will not replace any existing library subscription and will not be put at the disposal of any library. Subscriptions should be sent to D. Reidel Publishing Company, P.O. Box 17, 3300 AA Dordrecht, Holland, or to any subscription agent. Private subscriptions should be sent direct to the publisher. For advertisement rates and prices of back volumes apply to the publisher.

This journal is registered at the Copyright Clearance Center, 21 Congress Street, Salem, MA 01970, U.S.A.

The code on the first page of an article indicates the copyright owner's consent that copies of the article may be made for personal or internal use, or for the personal or internal use of specific clients. This consent is given on the condition that the copier pay through the Copyright Clearance Center the per-copy fee stated in the code for copying beyond that permitted by Sections 107 or 108 of the U.S. Copyright Law. (Articles published prior to 1979 may be copied for a fee of $\$ 1$ per copy, also payable through the Center.) This consent does not extend to other kinds of copying, such as for general distribution, for advertising or promotional purposes, for creating new collective works, or for resale.

The permission to publish in this journal entails the author's irrevocable and exclusive authorization of the publisher to collect any sums or considerations for copying or reproduction payable by third parties (as mentioned in article 17, paragraph 2, of the Dutch Copyright Act of 1912 and in the Royal Decree of June 20, 1974 (S.351) pursuant to article 16b of the Dutch Copyright Act of 1912) and or to act in or out of court in connection herwith.

Copyright $\odot 1980$ by D. Reidel Publishing Company. Printed in The Netherlands. Second Class Postage Paid at New York, N.Y. (USPS 509100). U.S. Mailing Agent: Expediters of the Printed Word Ltd., 527 Madison Avenue (Suite 1217), New York, NY 10022. 


\section{SPACE SCIENCE REVIEWS}

Volume 27 Nos. $3 / 41980$

\section{STELLAR HYDRODYNAMICS \\ Proceedings of the 58th Colloquium of the International Astronomical Union}

held in Los Alamos, U.S.A., August 12-15, 1980

edited by

ARTHUR N. COX

Los Alamos Scientific Laboratory

and

DAVID S. KING

University of New Mexico 


\section{PUBLISHER'S NOTE}

The publication in Space Science Reviews of the Proceedings of the 58th Colloquium of the IAU, in camera-ready format as typed and supplied by the authors and editors, marks a unique departure from our normal practice that enables the papers to be brought to readers not only in a much shorter time than is usual, but due to the lesser cost of production permits the inclusion of very many more printed pages, which we trust shall please all the persons concerned. 
TABLE OF CONTENTS

Preface

Introduction

List of Participants

I. 1D, 2D, AND 3D COLLAPSE OF INTERSTELLAR CLOUDS

W. M. TSCHARNUTER / 1D, 2D, and 3D Collapse of Interstellar Clouds (Review)

P. BODENHEIMER, J. E. TOHLINE, and D. C. BLACK / Fragmentation in Rotating Isothermal Protostellar Clouds

A. P. BOSS / Collapse, Equilibrium, and Fragmentation of Rotating, Adiabatic Clouds

KARL-HEINZ A. WINKLER and MICHAEL J. NEWMAN / On Solar Type Protostars

R. H. DURISEN and J. E. TOHLINE / A Numerical Study of the Fission Hypothesis for Rotating Polytropes

RICHARD I. KLEIN, MAXWELL T. SANDFORD II, and RODNEY W. WHITAKER / Two-Dimensional Radiation-Hydrodynamics Calculations of the Formation of O-B Associations in Dense Molecular Clouds

II. SOLAR PULSATIONS

HENRY A. HILL / Solar Pulsations (Review)

LAWRENCE D. CLOUTMAN / Numerical Simulation of the Solar Granulation

JERRY D. LOGAN and HENRY A. HILL / Radiative Damping of Gravity Waves in the Solar Atmosphere

MYRON A. SMITH / Nonradial Oscillations: The Cause of Macroturbulence in Late-Type Stars?

III. $\beta$-CEPHEI AND 53 PERSEI VARIABLES

JOHN R. PERCY / Beta Cephei and Related Stars (Review)

ARTHUR N. COX and STEPHEN W. HODSON / Linear and Nonlinear Pulsations of $\beta$ Cephei Stars 
ARTHUR YOUNG and INGEMAR FURENLID / Fast Time-Resolution Spectroscopy of BW Vulpeculae

WILLIAM DEAN PESNELL and ARTHUR N. COX / The Light and Velocity Curve Bumps for BW Vulpeculae

ANDREW P. ODELL / Non-Radial Pulsation Models of the H-Alpha Profile in BW Vulpeculae

M. JERZYKIEWICZ and C. STERKEN / Pulsation Modes and Luminosities of the $\beta$ Cephei Stars

J.-P. SAREYAN, J.-M. LE CONTEL, J.-C. VALTIER, and D. DUCATEL / Are there Different Types of Variability Among B Stars?

IV. $\delta$ SCUTI AND DWARF CEPHEID VARIABLES

MICHEL BREGER / Delta Scuti Stars and Dwarf Cepheids: Review and Pulsation Modes (Review)

L. A. BALONA and R. S. STOBIE / Mode Discrimination in Nonradially Oscillating Stars from Light, Colour, and Velocity Observations

D. W. KURTZ / Radial and Nonradial Oscillations in Delta Scuti Stars

G. KJAERGAARD ANDREASEN, P. M. HEJLESEN, and J. OTZEN PETERSEN / Theoretical Evolution Sequences for Homogeneous and Two-Zone Models of Delta Scuti Variables

V. CEPHEIDS OF POPULATIONS I AND II

J. P. COX / Recent Work on Cepheid Variables (Review)

R. S. STOBIE / Double-Mode Cepheids (Review)

MINE TAKEUTI / The Critical Frequency in the Stellar Pulsation Theory

B. C. COGAN, A. N. COX, and D. S. KING / Ful1 Amplitude Models of 15 Day Cepheids

JOHN R. PERCY and NANCY REMAGE EVANS / HR 7308: A Unique Cepheid

G. BURKI and M. MAYOR / HR 7308, A Short Period Cepheid with Variable Amplitude 
MICHEL BREGER / The Unusual Classical Cepheid HR 7308: 19661969

NORMAN R. SIMON / An Extended Work Integral for Pulsating Stars

LEO CONNOLLY / Ultra-Short Period Cepheids in the LMC

EDWARD G. SCHMIDT / The Cepheid Luminosity Scale

VI. RED VARIABLES

JULIUS H. CAHN / Pulsation Properties of Mira Long Period Variables (Review)

RONALD C. KIRKPATRICK / The Evidence for Planetary Progenitor Rotation and for the Long Term Acceleration of the Ejected Nebular Shell.

W. DEAN PESNELL and JAMES M. COGGINS / Spherical Oscillation Patterns

VII. RR LYRAE AND BL HERCULIS VARIABLES

ARTHUR N. COX / RR Lyrae and BL Herculis Variables (Review)

KEITH DESPAIN / Low-Mass Evolution from He Ignition to Beyond the Horizontal Branch

PETER W. COLE and ROBERT G. DEUPREE / The Core Helium Flash JORGEN OTZEN PETERSEN / Bump Masses and Radii of BL Herculis Variables

S. W. HODSON, A. N. COX, and D. S. KING / Nonlinear Calculations for BL Her Stars

A. MANDUCA and R. A. BELL / The Absolute Magnitudes of RR Lyrae Stars

K. J. BORKOWSKI / Blazhko Effect in the RR Lyrae Variables as a Result of Double Mode Pulsation

VIII. R CORONAE BOREALIS PULSATIONS

DAVID S. KING / R Coronae Borealis Pulsations (Review)

J. P. COX, D. S. KING, A. N. COX, J. C. WHEELER, C. J. HANSEN, and S. W. HODSON / Pulsations of the R Coronae Borealis Stars 


\section{SUPERNOVAE}

RICHARD L. BOWERS and J. R. WILSON / Core Collapse, Bounce and Shock Propagation (Review)

S. W. FALK / The Light Curve Epochs of Supernovae Explosions (Review)

J. E. TOHLINE, J. M. SCHOMBERT, and A. P. BOSS / The Effect of Rotation on the Hydrodynamics of Stellar Collapse

KEN'ICHI NOMOTO / White Dwarf Models for Type I Supernovae and Quiet Supernovae, and Presupernova Evolution

J. ROBERT BUCHLER, MARIO LIVIO, and STIRLING A. COLGATE / Supernova Explosions - The Role of a Rayleigh-Taylor Instability

ERIC M. JONES, BARHAM W. SMITH, and WILLIAM C. STRAKA / The Effect of Stellar Structure on Supernova Remnant Evolution

J. ROBERT BUCHLER, MANUEL BARRANCO, and MARIO LIVIO / X-Ray Burst Sources - A Simple Two Zone Model

MICHAEL J. NEWMAN and ARTHUR N. COX / One-Dimensional Hydrodynamics of Asteroid-Neutron Star Collisions

R. CANAL, J. ISERN, and J. LABAY / Neutron Star Formation by Collapse of White Dwarfs

X. WHITE DWARF PULSATIONS

JOHN T. MCGRAW / White Dwarf Pulsations: A Review (Review)

EDWARD L. ROBINSON and S. O. KEPLER / The ZZ Ceti Stars and the Rate of Evolution of White Dwarfs

SUMNER G. STARRFIELD, ARTHUR N. COX, and STEPHEN W. HODSON /

A New Instability Strip for Hot Degenerates

TERRY W. EDWARDS / Thermodynamic Transport Properties in Dense Stars

XI. NOVAE

S. STARRFIELD / Hydrodynamic Studies of the Nova Outburst (Review) 
RONALD L. GILLILAND / Hydrodynamic Modeling of Mass Loss from Cataclysmic Variable Secondaries

WARREN M. SPARKS and SIEGFRIED KUTTER / A Wave Model for Dwarf Novae

XII. EFFECT OF ROTATION AND MAGNETIC

FIELDS ON PULSATION

HIDEYUKI SAIO / Rotational and Tidal Perturbations of Nonradial Oscillations in a Polytropic Star

P. SMEYERS / Rotational Modes in a Uniformly Rotating Star

M. GOOSSENS and D. BIRONT / The Effect of a Magnetic Field on Stellar Pulsations as a Singular Perturbation Problem

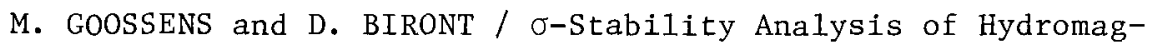
netic Instabilities in Stars with Toroidal Magnetic Fields

INDEX OF NAMES

INDEX OF SUBJECTS 